compromise.

In addition to genetic aspects of congenital syndromes, the importance of environmental factors is apparent from the following report.

Mobius' syndrome and misoprostol attempted abortion. In a study at the Fetal Diagnosis and Treatment Centre, University of Toronto, Canada, among mothers of 96 infants with Mobius' syndrome, 47 (49\%) had used misoprostol in the first trimester of pregnancy, as compared with $3(3 \%)$ mothers of 96 infants with neural-tube defects as controls. Attempted abortion with misoprostol increases risk of Mobius' syndrome in infants (Pastuszak AL, Schuler L, SpeckMartins CE et al. Use of misoprostol during pregnancy and Mobius' syndrome in infants. $\mathrm{N}$ Engl J Med June 25, 1998;338:1881-5).

\title{
BILATERAL PERIVENTRICULAR NODULAR HETEROTOPIA
}

Two unrelated boys, ages 8 and 5 years, with a syndrome of bilateral periventricular nodular heterotopia $(\mathrm{BPNH})$, regional cortical dysplasia, mild mental retardation, and frontonasal malformation (FNM) are reported from the Instituto di Neuropsychiatria Infantile, University of Pisa, Italy, and the Institute of Human Genetics, University of Minnesota Medical School, Minneapolis, MN. Other manifestations of this BPNH/FNM syndrome, common to both children, included frontal bossing, widow's peak, epicanthal folds, low set ears, and cryptorchidism. The cause is probably genetic, possibly X-linked. (Guerrini R, Dobyns WB. Bilateral periventricular nodular heterotopia with mental retardation and frontonasal malformation. Neurology Aug 1998;51:499-503). (Reprints: Dr Renzo Guerrini, Institute of Child Neurology and Psychiatry, Via dei Giacinti, 2, 56018 Calambrone, Pisa, Italy).

COMMENT. BPNH usually occurs in females with refractory epilepsy and normal intelligence, and a gene mapped to chromosome Xq28. Several other BPNH syndromes are described, affecting males only, and associated with mental retardation and epilepsy but without facial anomalies. Frontonasal malformation (FNM) may occur alone or with intracranial cysts or midline brain defects, including encephalocele, corpus callosum lipoma, and holoprosencephaly, but not BPNH. The above syndrome of BPNH/FNM is unusual.

Multilobar polymicrogyria, drop attack seizures, and sleeprelated electrical status epilepticus is another syndrome reported in 9 patients followed for periods up to 19 years at the University of Pisa, Italy (Guerrini R, Genton P, Bureau M et al. Neurology Aug 1998;51:504-512). Seizures began between 2 and 5 years of age and ceased between 5 and 12 years. The good seizure outcome in these children with polymicrogyria contrasts with most cortical malformations and argues against early surgical intervention.

Lissencephaly, types, radiological grades, and genetic basis, are reviewed from the Medical Genetics Center, Ibn Sina Hospital, Kuwait; and Dalhousie University, Halifax, Canada (Sabry MA, Farah SA, Farag TI, I Am Acad Child Adolesc Psychiatry Sept 1998;37:899). Clinically, lissencephaly is classified as type I (Miller-Dieker syndrome, Norman Roberts syndrome, X-linked, and isolated lissencephaly sequence); type II or cortical dysplasia (congenital muscular dystrophy, Walker-Warberg, Fukuyama syndromes); type III lissencephaly, with corpus callosum agenesis, arthrogryposis, and other anomalies. Radiologically, 6 grades dependent on degrees of agyria, pachygyria, and heterotopic tissue. Genes are mapped to various chromosomes: $17 \mathrm{p} 13,2 \mathrm{p} 11,2 \mathrm{q} 13, \mathrm{Xq} 22$, and 9q31. 